\title{
Trabalhonecessário
}

Issn: 1808 - 799X

ano 13, número $20-2015$

\section{A PRODUTIVIDADE DA ESCOLA IMPRODUTIVA 30 ANOS DEPOIS: REGRESSÃO SOCIAL E HEGEMONIA ÀS AVESSAS}

Gaudêncio Frigotto ${ }^{1}$

\section{Resumo}

No presente texto, busco revisitar, trinta anos depois, o livro $A$ produtividade da escola improdutiva: um (re)exame da relação entre educação e estrutura econômico-social capitalista, destacando a concepção teórica e metodológica centrada no materialismo histórico. A partir deste referencial, aprofundado ao longo de três décadas, sublinho as mudanças na base material e política das relações sociais capitalistas e seu caráter regressivo em todas as esferas da sociedade e cujo preço recai na perda de direitos da classe trabalhadora. No campo educativo, surgem novas noções - sociedade do conhecimento, qualidade total, formação por competências, empregabilidade - que radicalizam o caráter ideológico da noção de capital humano, mascarando a regressão social e educacional subjacente. Nas considerações finais, como interpelação mais aguda do balanço das três décadas, sublinho o desafio no campo da esquerda brasileira, que atua na educação, mas não só com uma melhor compreensão e concretização da relação entre a produção teórica e a ação política.

Palavras-chave: Capital humano. Classes sociais. Regressão social e educacional. Contra-hegemonia.

1 Professor do Programa de Pós-Graduação em Políticas Públicas e Formação Humana da Universidade do Estado do Rio de Janeiro. 


\section{Trabalhonecessário}

Issn: 1808 - 799X

ano 13, número $20-2015$

\section{Abstrat}

In this text, I try to revisit, thirty years later, the book The productivity of unproductive school: a (re)view of the relationship between education and social economic capitalist structure, highlighting the theoretical and methodological concept based on historical materialism. From this reference, that was deepened over three decades, I underline the changes on the material and political basis of capitalist social relations, its regressive character in all spheres of society and the price that relapses on the rights of the working class. In the educational field emerge new notions - the knowledge society, total quality, formation for competence, employability - that radicalize the ideological character of human capital notion, masking the social and educational regression underlying. In the final considerations, as more acute interpellation of the balance of the three decades, I emphasize the challenge in the field of Brazilian Left that works with education, not only with a better understanding, but also with the implementation of the relationship between the theoretical production and political action.

Keywords: Human capital, social classes, social and educational regression, counter-hegemony.

\section{Resumen}

En el presente texto, busco revisitar, treinta años después, el libro La productividad de la escuela improductiva: un (re)examen de la relación entre la educación y la estructura económico social capitalista, destacando la concepción teórica y metodológica centrada en el materialismo histórico. A partir de este referencial, profundizado a lo largo de tres décadas, señalo los cambios en la base material y política de las relaciones sociales capitalistas y su carácter regresivo en todas las esferas de la sociedad y cuyo precio recae en la pérdida de los derechos de la clase trabajadora. En el campo educativo surgen nuevas ideas - la sociedad del conocimiento, la calidad total, la formación de competencias, la 


\section{Trabalhonecessário}

Issn: 1808 - 799X

ano 13 , número $20-2015$

empleabilidad - que radicalizan el carácter ideológico de la noción de capital humano mascarando la regresión social y educacional subyacente.. En las consideraciones finales, como interpelación más aguda del balance de las tres décadas, subrayo el desafío en el campo de la izquierda brasileña que actúa en la educación, pero no sólo con una mejor comprensión y concretización de la relación entre la producción teórica y la acción política.

Palabras clave: Capital humano, clases sociales, regresión social y educacional, contra-hegemonía.

Este texto teve como origem a mesa de enceramento do II Intercâmbio Nacional dos Grupos de Pesquisa em Trabalho e Educação (INTERCRÍTICA), realizado na Universidade Federal do Pará, no período de 26 a 28 de agosto de 2014. O objetivo da mesa foi o de reunir um conjunto de autores cujas obras constituíram-se referência, ao longo dos últimos trinta anos, para os estudos e os debates sobre a relação trabalho e educação².

O livro A produtividade da escola improdutiva: um (re)exame da relação entre educação e estrutura econômico-social capitalista, publicado em 1984, buscou efetivar uma análise antagônica à visão economicista da educação sintetizada na noção ou na ideologia de capital humano. Uma crítica, ao mesmo tempo, de ordem epistemológica, filosófica e política para evidenciar o reducionismo na concepção de ser humano, sociedade, trabalho e educação daquela noção ideológica.

Um livro que foi produzido numa conjuntura, no plano internacional, em que as políticas keynesianas e do Estado de bem-estar social não só não podiam se

\footnotetext{
2 A Sessão de encerramento teve como tema Três décadas de produção na área de trabalho $e$ educação no Brasil: que lições ficaram? Cada autor foi interpelado a fazer um breve balanço sua obra. As obras indicadas e os autores, pela ordem de lançamento foram: $A$ produtividade da escola improdutiva (1984), Gaudêncio Frigotto; Pedagogia da fábrica (1985), Acacia Kuenzer; Politecnia, escola unitária e trabalho (1989), Lucília Machado; Opção trabalho (1989), Celso Ferretti, e A escola de Gramsci (1992), Paolo Nosella.
} 


\section{Trabalhonecessário}

Issn: 1808 - 799X

ano 13, número $20-2015$

generalizar no sistema capitalista, mas estavam sendo restringidas em face a um novo ciclo de crise desse sistema, cujo agravamento se estende até o presente. No plano nacional, uma conjuntura de declínio da ditadura civil-militar que, sob o ideário do capital humano, efetivou reformas educativas em todos os níveis de ensino. Um contexto em que o pensamento social de esquerda retomava a crítica, tanto ao projeto societário que motivou o golpe civil-militar, quanto a ditadura que o sustentou por mais de 20 anos, sob a força das armas e do arbítrio ${ }^{3}$.

Do ponto de vista teórico e epistemológico, vivia-se um contexto no Brasil de expansão da pós-graduação nas ciências sociais e humanas e a incorporação, em alguns programas de pós-graduação em educação, da leitura de obras de Marx e outros autores da tradição marxista. A linha de Filosofia de Educação, coordenada pelo professor Dermeval Saviani, iniciada no ano de 1978, no Programa de Pós-Graduação da PUC/SP, tomou explicitamente como referencial básico a leitura e o debate de obras, em especial, de Karl Marx, Antônio Gramsci e de Lênin (Vladimir Ilitch Lênin). O livro A produtiviadade da escola improdutiva resultou da tese produzida nesse programa, sob a orientação de Dermeval Saviani.

No esforço de apreender o sentido desta obra, tinta anos depois, abordarei três aspectos. No prmeiro, busco situar o escopo da concepção teórica e metodológica que orientou a análise que a obra traz. No segundo, à luz deste referencial aprofundado ao longo dessas três décadas, procuro destacar o que permanece e o que se altera na base material do sistema capitalista mundial e da sociedade brasileira que radicalizam o caráter excludente das relações sociais e refinam as noções derivadas do capital humano, as quais buscam mascarar o que está subjacente. Por fim, atenho-me a alguns aspectos das lições tiradas ao longo destes trinta anos e um breve apontamento sobre a crítica ao ensino médio integrado feita por Paolo Nosellça na sua exposição oral no INTERCRITICA II.

\footnotetext{
${ }^{3}$ Ver a este respeito as análises de André Dreyfus ( 1981). Ver, também, o filme documentário de Danilo Tavares: Um dia que durou 21 anos.
} 
Issn: 1808 - 799X

ano 13, número $20-2015$

\section{Gênese e centralidade da construção teórica e metodológica na produção do livro}

A análise contida nesta obra buscou seus referenciais, como assinalamos acima, na herança da concepção materialista histórica e em seu método de compreensão de como se produzem os fenômenos sociais. Vale dizer, o método que busca desvelar o que está subjacente ao aparente dos fatos e das ações humanas, e que os constituem como o são, é o passo fundamental para uma ação consequente no plano da práxis para a sua alteração.

Um primeiro aspecto de ordem teórico-metodológica é de que a tese, e posteriormente o livro, tem sua gênese no processo de elaboração da dissertação de mestrado, orientada pelo economista Cláudio de Moura Castro, cujo referencial era e continua sendo o pensamento liberal, e o funcionalismo positivista, metodologicamente. Moura Castro, que fez o curso de mestrado na Universidade de Yale e o doutorado na Universidade de Vanderbilt, nos EUA, e Carlos Geraldo Langoni, com doutorado em Chicago, também nos EUA, foram os primeiros a trazer o ideário da "teoria" do capital humano para o Brasil. Moura Castro, entretanto, é quem inicia a teoria na Pontifícia Universidade Católica do Rio de Janeiro (PUC-RJ) e, em seguida, no Instituto de Estudos Avançados em Educação (lesae), da Fundação Getulio Vargas, cria a disciplina Economia da Educação ${ }^{4}$.

\footnotetext{
${ }^{4} \mathrm{~A}$ influência deste intelectual na política educacional brasileira de cunho liberal e neoliberal é central desde a década de 1970. Moura Castro é um dos interlocutores permanentes dos ministros de Educação e das audiências púbicas no Congresso Nacional, mormente sobre a questão da educação técnica e profissional. É adepto confesso da dualidade educacional, um ensino profissional para quem se destina ao duro ofício de trabalho como postulava o iluminista Destutt de Tracy (1754-1836) e uma escola de cunho geral para os filhos da burguesia.. Numa entrevista à revista Veja, ele explicita que finalmente sua tese desta separação foi atendida. Em meados de 1990, estava no Banco Interamericano de Desenvolvimento (BID) e assessorava o ministro Paulo Renato, interessado em um empréstimo para o ensino técnico. Mas a proposta esbarrava no elitismo e na distorção dos cursos. Diante do impasse, desenterrei a minha proposta que foi aceita e implementada. Quem quisesse o vestibular escolheria o ramo acadêmico. Quem quisesse a profissão iria para o ramo técnico, depois de formado no ensino médio. Ou, então, poderia fazer o
} 


\section{Trabalhonecessário}

Issn: 1808 - 799X

ano 13 , número $20-2015$

Desta localização histórica advêm observações de diferentes naturezas à luz do que é o motor da dialética materialista histórica: a contradição. Primeiramente de que, no escopo das contradições da ditadura civil-militar, em 1972, foi criado o Instituto de Estudos Avançados em Educação (lesae), na Fundação Getulio Vargas (FGV), e, em seguida, em 1973, o curso de mestrado em Educação.

O caráter contraditório na constituição do lesae situa-se no fato de que um sistema ditatorial detém a dominação, mas não a hegemonia. A FGV, por um lado, por ser uma instituição confiável ao regime, acabou tendo em seus quadros diretivos Raymundo Muniz de Aragão, ex-ministro da Educação do primeiro presidente da ditadura civil-militar, Humberto Castello Branco. Por outro lado, também acolheu pesquisadores críticos ao regime como o liberal Anísio Teixeira, cuja morte deu-se em circunstâncias suspeitas, e Durmeval Trigueiros Mendes, aposentado, arbitrariamente em1969, pelo Al5.

A tarefa de consolidar o curso de mestrado implicou a contratação de quadros. Uma pesquisadora-chave para a consolidação do lesae e de inclusão de pesquisadores de pensamento crítico foi Maria Julieta Costa Calazans. Ela que saiu do Brasil para não ser presa, pois atuava no Nordeste na educação e mobilização dos movimentos sociais do campo, acabou sendo contratada para ajudar na implantação do curso de mestrado em estudos avançados em educação. Sua inclusão no lesae se dá de forma transversa, como ela mesma expõe, em entrevista a Maria Celina D'Araujo.

No final de 1969, voltei para o Brasil depois de um doutorado na França e, a convite de Edson Machado de Sousa, fui para o

médio, simultaneamente (CASTRO, 2012). Moura Castro está declarando a paternidade do Decreto 2.208/1997. Em seguida, reclama da mudança feita em 2004 mediante o Decreto 5.154/2004. Após a mudança de governo, entraram no MEC os inconformados com a separação. Tentaram voltar atrás, mas, em virtude da grita, somente as escolas federais tornaram a integrar 0 acadêmico ao técnico. As razões para juntá-los permanecem misteriosas para a cabeça simplória deste autor. A bandeira desfraldada era uma tal "politecnia", criada por Gramsci, lá pelos anos 1920, enquanto morava na cadeia. Prescrevia um ensino combinando as disciplinas técnicas com as acadêmicas e com o trabalho. Mais que isso, não entendi (ibid.). 


\section{Trabalhonecessário}

Issn: 1808 - 799X

ano 13, número $20-2015$

Centro Nacional de Recursos Humanos do Ipea, para desenvolver um projeto que faria uma tipologia da mão de obra brasileira no setor primário. O Ipea verificou que era impossível fazer aquilo sozinho, porque havia um enorme trabalho de campo, e decidiu fazer um convênio com a Fundação Getulio Vargas. (...). A Fundação então me convidou para vir para o IESAE quando terminasse a pesquisa, o que, afinal, só aconteceu no fim de 1972. (D`ARAUJO, 1999, p. 214.)

Calazans teve um enorme mérito na estratégia de contratação, inicialmente por projetos e, depois, para o quadro de pesquisadores do pensamento social crítico tais como: Luiz Antônio Constant Rodrigues da Cunha, Elter Dias Maciel, Cândido Grzybowski, Victor Vicente Valla, Osmar Fávero, Carlos Plastino. Destes, a partir de 1977, após a conclusão do meu mestrado, vim a ser quando lá atuei por dezoito anos.

O segundo aspecto é de que meu orientador da dissertação, à época indicado pela coordenação do curso, Claudio de Moura Castro, teve, contraditoriamente, uma contribuição fundamental para o que seria o livro $A$ produtividade da escola improdutiva. Primeiramente, por me fazer entender, no detalhe e na prática, o que é um trabalho de pesquisa na ótica funcional positivista e empiricista, centrado na "teoria" dos fatores. Em segundo lugar, pela sua qualidade de cultivar o debate e gostar da polêmica e respeitar, pelo menos em parte, o pensamento oposto ou antagônico. O tema da dissertação expressa esta particularidade: Efeitos cognitivos da escolaridade do Senai e da escola acadêmica: existe uma escola para cada classe social? (FRIGOTTO, 1977). Uma síntese da dissertação sobre o sentido ideológico e a perspectiva de adestramento nos processos formativos do Senai, naquele, contexto, está contida no trabalho Fazendo pelas mãos a cabeça do trabalhador (FRIGOTTO, 1983).

Da formação teórica construída ao longo do curso de doutorado derivam dois aspectos que foram sendo aprofundados no debate e no diálogo com colegas na atividade profissional, inicialmente no lesae/FGV até sua extinção em 1989, na Universidade Federal Fluminense, até o final da década de 1990, e, no 


\section{Trabalhonecessário}

Issn: 1808 - 799X

ano 13 , número $20-2015$

presente, na Universidade do Estado do Rio de Janeiro. O primeiro refere-se à concepção materialista histórica da realidade e ao método dialético para entender como os seres humanos produzem socialmente as condições de sua existência. O segundo, ligado a este, de que a teoria sem a práxis reduz-se a uma abstração metafísica inútil.

A síntese dessa concepção e método contidos na obra de Karl Marx é feita de forma irreparável por seu parceiro de produção intelectual e de luta política, Friedrich Engels, no breve discurso de despedida ao lado do túmulo de seu amigo, destacando as duas leis fundamentais de seu legado.

Assim como Darwin descobriu a lei do desenvolvimento da natureza orgânica, Marx descobriu a lei do desenvolvimento da história humana: o fato, tão simples, mas oculto sob uma manta ideológica, de que o homem necessita, em primeiro lugar, de comer, beber, ter um teto e vestir-se antes de poder fazer política, ciência, arte, religião etc.; de que, portanto, a produção dos meios de vida imediatos, materiais, e, por conseguinte, o grau de desenvolvimento econômico objetivo de um povo dado ou durante uma época dada forma a base sobre a qual as instituições estatais, as concepções jurídicas, a arte e inclusive as ideias sobre religião do povo em questão tem se desenvolvido, e à luz das quais devem, por tanto, ser explicadas, em vez do contrário, como havia sido o caso até então.

Mas isso não é tudo. Marx também descobriu a lei especial do movimento que governa o atual modo capitalista de produção, e a sociedade burguesa que este modo de produção tem criado. A descoberta da mais-valia iluminou de imediato o problema, que todas as investigações anteriores, tanto as dos economistas burgueses como as dos críticos socialistas, haviam estado tratando de resolver, navegando no obscuro. (Friedrich Engels, $1883)^{5}$

No denso livro de Karel Kosik - Dialética do concreto -, encontramos, no plano filosófico e epistemológico, o contraponto entre as concepções dominantes "metafísicas", funcionalistas e positivistas da realidade social e do materialismo

\footnotetext{
5 Texto retirado do Blog de Debate ISKRA - Teoria e Política Marxista. (Acesso em: 5/7/2013.)
} 


\section{Trabalhonecessário}

Issn: 1808 - 799X

ano 13 , número $20-2015$

histórico. Ao explicitar com rigor a lei do desenvolvimento histórico ${ }^{6}$ como 0 monismo materialista, ele nos dá uma dupla chave analítica: a de distinguir as visões economicistas de sociedade que elidem as relações, o conflito e o antagonismo das classes sociais da concepção materialista de economia ou do econômico, além do critério para qualificar a práxis mediatamente revolucionária das "práxis" reprodutoras da ordem social capitalista.

O monismo materialista que concebe a realidade como o complexo constituído e formado pela estrutura econômica e, portanto, por um conjunto de relações que os homens estabelecem na produção e no relacionamento com os meios de produção, pode constituir-se base de uma coerente teoria das classes e ser o critério objetivo para a distinção entre mutações estruturais, que mudam o caráter da ordem social, e mutações derivadas, secundárias, que modificam a ordem social sem, porém, mudar essencialmente seu caráter. (KOSIK, 1976, p.105)

Aqui, o econômico não é concebido como um fator, mas como a relação social fundamental, mediante a qual o ser humano pelo trabalho produz as condições materiais de sua produção e reprodução como ser da natureza. "A economia não trata de coisas, mas de relações entre pessoas e, em última instância, entre classes; estas relações estão, porém, sempre ligadas a coisas e aparecem como coisas" (ENGELS, apud BARATA-MOURA, 1998, p.120).

O caráter fundamental, imperativo e imprescindível da atividade produtiva não deriva, como sublinha Kosik, de ser ela uma atividade superior às demais, mas do fato de que sem esta os seres humanos não poderão dedicar-se à arte, ao estudo, à cultura, do lazer etc. É neste sentido que Marx situa o trabalho na esfera da necessidade, como condição para a esfera da liberdade, da escolha e da fruição. Desta compreensão é que Lukács, a partir da obra de Marx, na

6 O sentido de lei no plano humano social, como Marx e Engels a entendem, expressa o movimento e o processo histórico que tem como fundamento a base das relações sociais $e$ econômicas, estas não como um fator, mas como aquelas que, ao longo da história, definem a forma mediante a qual os seres humanos têm acesso ao comer, ter um teto, poder vestir-se, etc,... Como indica Raymond Williams: "então, devemos dizer que quando falamos de 'base' (aspas do autor), estamos falando de um processo e não de um estado" (WILLIAMS, 2011, p. 47). 


\section{Trabalhonecessário}

Issn: 1808 - 799X

ano 13, número $20-2015$

Ontologia do ser social, nos mostra que o ser humano não nasce humano, mas produz-se e reproduz-se pelo trabalho. Este, não esgota todas as atividades humanas, todavia as preside necessariamente.

Coerente, pois, com esse horizonte teórico, de forma indicativa na brevidade deste texto, sinalizo a seguir o que se altera na base material das relações sociais capitalistas, e como a noção de capital humano, concepção básica do economicismo na educação, e a luta teórica e política assumem novas determinações e num sentido regressivo.

\section{Tempos de crise do capital, regressão social e de hegemonia às avessas}

A ideia central deste item é primeiramente afirmar que o que não se altera ao longo dos 30 anos, mas se aprofunda, é a concepção materialista histórica de realidade social e o método dialético na sua apreensão. Em segundo lugar, e à luz deste referencial, quer mostrar que, no transcorrer dessas três décadas, as relações sociais capitalistas adotam um caráter cada vez mais opaco, violento e regressivo, como resposta ao aprofundamento e à especificidade, que assumem a crise do capital. Crise que, como mostra Mészáros (2000), diferente das demais produzidas pelo caráter contraditório do modo de produção capitalista, é atualmente universal, global, contínua e cada vez mais irreversível, podendo assumir um caráter explosivo. Universal, porque alcança todas as esferas da vida, a economia, o trabalho, a natureza, a educação, a cultura, a política, a ética etc. Global, porque não se localiza mais em um ponto, mas atinge o planeta em maior ou menor intensidade ${ }^{7}$. Disto decorre o surgimento de novas noções ideológicas que, como analisarei adiante, atualizam e, ao mesmo tempo, agravam o caráter de fetiche da noção de capital humano. Noções ideológicas, portanto, que

\footnotetext{
${ }^{7}$ Além da referência da análise de István Mészáros, ver David Harvey (2010 e 2013).
} 


\section{Trabalhonecessário}

Issn: 1808 - 799X

ano 13, número $20-2015$

buscam mascarar o que está subjacente à crise do capital e suas consequências funestas para a vida da maioria dos seres humanos ${ }^{8}$.

O subtítulo do livro: um (re)exame das relação entre educação e estrutura econômico social capitalista indica que, até a década de 1950, a educação no contexto daqueles países em que a revolução burguesa se efetivou em termos clássicos, mesmo que dual, era concebida como um direito social e subjetivo. A formulação da noção de capital humano por Theodore Schultz emerge, por um lado, da crise das políticas keynesianas e da do Estado de bem-estar social, no combate à desigualdade entre nações, classes e grupos sociais e, por outro, da forma invertida dos intelectuais burgueses entenderem a natureza subjacente e estrutural da crise do capital e as políticas de enfrentamento. O (re)exame também busca explicitar o debate sobre as relações entre a educação escolar, o desenvolvimento econômico e o eixo da luta contra-hegemônica no plano teórico e político do economicismo na educação.

A base empírica de Schultz no desenvolvimento do que foi denominada de "teoria" do capital humano foi a observação de que as famílias que investiam mais em educação formal e em saúde tinham retornos maiores do que as demais. Como positivista e empirista, ao ver a dificuldade de mensurar a saúde, abandona este indicador e fica apenas com a educação. Ao final do seu experimento, na comparação entre o Produto Interno Bruto (PIB) e a escolaridade, Schultz encontra uma correlação altíssima entre ambas. Daí conclui, sem levar em conta o processo histórico marcado pela desigualdade entre as classes sociais e nações, que o investimento em educação é algo tão ou mais rentável que os demais investimentos.

Ninguém pode negar a importância do conhecimento científico e cultural no desenvolvimento das formas dos seres humanos qualificarem suas vidas em todas as dimensões. Trata-se, por um lado, de analisar a natureza e o sentido desse conhecimento no travejamento das relações sociais em sociedades de classe. Ou, a quantos, e a quem serve. 
Issn: 1808 - 799X

ano 13 , número $20-2015$

Por outro lado quer-se demonstrar que Schultz é expressão dos intelectuais da burguesia que por condição de classe ignoram o que Engels destaca na citação acima: "a lei especial do movimento que governa o atual modo capitalista de produção, e a sociedade burguesa que este modo de produção tem criado e, portanto navegam no obscuro". Ou seja, estes intelectuais buscam explicar a sociedade e suas relações sociais pelo Estado, pelo sistema jurídico, pela educação, pela saúde etc. e não entendem que o Estado, o sistema jurídico e político, a educação, a saúde etc. são produtos das relações entre as classes sociais e que buscam, dialeticamente, reproduzir a ordem social da qual emergem.

O resultado é que a noção de capital humano sedimenta um reducionismo da concepção de ser humano a uma mercadoria ${ }^{9}$; de trabalho, ao confundir a atividade vital que produz e reproduz o ser humano e que é pressuposto das demais atividades humanas, à venda da força de trabalho humana (emprego); de sociedade, ao tomá-la como um contínuo dos mais pobres aos mais ricos, ignorando a estrutura desigual e antagônica das classes sociais; de classe social, tomando-a por fatores isolados e independentes na compreensão da sociedade e, finalmente, de educação, de um direto social e subjetivo a uma concepção mercantil de formação humana ${ }^{10}$.

\footnotetext{
9 Pesquisadores da Universidade de Frankfurt que, anualmente e desde 1994, escolhem uma noção, de acordo com a sua avaliação, que expressa o que designa o termo alemão Unwort (não palavra). Trata-se de palavras do discurso público que são grosseiramente inadequadas ao tema designado e talvez até violem a dignidade humana. "Capital humano" foi escolhido, em 2004, como a não palavra, com a seguinte justificativa: degrada pessoas a grandezas de interesse meramente econômico. (Ver: ALTVATER, 2010, p. 75).

10 Não por acaso os organismos internacionais, intelectuais coletivos do sistema capital, passaram a produzir as diretrizes não só das relações econômicas, mas também das políticas educacionais. O Banco Mundial (BIRD) e o Banco Interamericano de Desenvolvimento (BID) centralizaram a orientação das políticas e sua disseminação para organismos e agências regionais e locais, com quadros formados por Universidades que dão a base teórico-ideológica a estes organismos e treinados dentro dos mesmos. No plano jurídico. a Organização Mundial do Comércio (OMC) vaise constituindo, acima dos Estados nacionais, no espaço de defesa dos interesses do grande capital mundial. $O$ documento-síntese com o receituário para ser aplicado em particular nos países endividados da periferia do sistema capitalista foi divulgado, sob o nome de Consenso de Washington, em 1989.
} 


\section{Trabalhonecessário}

Issn: 1808 - 799X

ano 13, número $20-2015$

Tanto este núcleo central quanto as perspectivas contra-hegemônicas tratadas no livro permanecem validas, mas alteradas na sua intensidade e na sua regressividade. Com efeito, o conteúdo central de A produtividade da escola improdutiva, pelo fato de que o ideário do capital humano constitui-se nas décadas de 1960 e 1970 na diretriz das reformas e políticas educacionais das ditaduras civil-militares da América Latina, em particular a do Brasil, o fulcro da análise foi mais o embate teórico visando entender e desconstruir esta noção e indicar o sentido da luta contra-hegemônica. Não se ateve, portanto, a não ser de modo mediado, às mudanças que vinham ocorrendo na materialidade das relações sociais capitalistas no plano mundial e na particularidade brasileira. Olhando 30 anos depois, percebo que aqui reside um limite. O que pode explicar, pelo menos em parte, este limite foi o fato de o livro ter sido produzido nos primeiros anos de um contexto do desenvolvimento das diferentes lutas, em todas as esferas da sociedade brasileira, na busca de dar fim à ditadura civil-militar. Por outro lado, o caráter específico da crise do capital ainda não estava apreendido pelas análises críticas.

A lacuna acima tornou-se objeto da obra Educação e crise do capitalismo real (FRIGOTTO, 1995). Este teve sua produção num contexto em que a crise do sistema capital se aprofunda e, ao mesmo tempo, dois fatos históricos alteram radicalmente a relação entre capital e trabalho e luta de classes. Ao longo das décadas de 1970 e 1980, simultaneamente define-se um novo salto tecnológico, que altera o modo dos seres humanos operaram com a matéria e, portanto, com as formas de produção e se processam contradições que levam ao colapso o socialismo real. A apropriação privada deste salto tecnológico e seu crescente processo de monopolização pelos megagrupos detentores do capital ampliam a desigualdade entre nações e permite uma avassaladora vingança do capital sobre as conquistas e direitos da classe trabalhadora. Os efeitos sobre a classe trabalhadora de suas condições de trabalho e de sua organização foi explosivo e potencia o que Marx observara em meados do século XIX. 


\section{Trabalhonecessário}

Issn: 1808 - 799X

ano 13, número $20-2015$

A máquina, triunfo do ser humano sobre as forças naturais, converte-se, nas mãos dos capitalistas, em instrumento de servidão de seres humanos a estas mesmas forças (...); a máquina, meio infalível para encurtar o trabalho cotidiano, prolonga-o, nas mãos do capitalista (...); a máquina, varinha de condão para aumentar a riqueza do produtor, empobrece-o em mãos do capitalista (MARX, apud PARIS, 2002, p. 235).

No âmbito das relações de poder internacionais, o colapso do socialismo real dá às forças do capital a chave para decretar o retorno às teses ultraconservadoras de que o capitalismo se constitui numa sociedade de tipo natural, por supostamente corresponder ao que é a natureza humana: a busca do bem individual próprio, o egoísmo produtivo. Doutrina esta que, no plano do pensamento crítico, paradoxalmente, assumiu o termo de neoliberalismo. Talvez, a denominação mais adequada fosse a de neoconservadorismo.

A coletânea Depois da queda: o fracasso do comunismo e o futuro do socialismo, organizada por Rubin Blackburn (1992), explicita a gênese e as implicações para o futuro do socialismo desse colapso, mas não um fracasso. Os dois pequenos textos do mais importante historiador marxista do século XX Erick Hobsbawm, que constam dessa coletânea, captam de forma aguda as determinações do colapso e a tese de que isso não significa o fim do projeto humano socialista. Os títulos Adeus a tudo aquilo e Renascendo das cinzas explicitam o esgotamento daquela importante experiência histórica e, ao mesmo tempo, falam da necessidade de repensar o socialismo do século XXI, aprendendo com as lições positivas e negativas do passado.

O sinal político da leitura ultraconservadora dos tempos que se seguem e das políticas contra a classe trabalhadora foi esgrimida pela Primeira-Ministra da Inglaterra na luta para desmantelar o sindicalismo daquele país. A tese de Margaret Thatcher é de que não via a sociedade, mas apenas indivíduos, portanto, para ela, a sociedade não existe. O que existe são individualidades, onde cada um luta por si. Retorna-se, pois, à tese ultraconservadora do homem econômico racional que, independente de sua origem e situação de classe social, 


\section{Trabalhonecessário}

Issn: 1808 - 799X

ano 13 , número $20-2015$

pode tomar a melhor decisão dentro dos seus interesses. Para esta visão de relações sociais, um desempregado e um Sem Terra podem tomar decisões vantajosas a seus interesses nas mesmas condições do patrão e do latifundiário.

As novas tecnologias, por sua vez, que combinam informação e microeletrônica dão, tanto ao capital produtivo quanto ao capital financeiro, enorme poder e mobilidade, permitindo desfazer-se de enormes contingentes de trabalhadores, além de eliminar ou flexibilizar as leis que protegiam os empregados e instaurar processos de superexploração. O capital já não necessita de toda a força de trabalho e já não há lugar para a estabilidade do trabalhador. Há apenas lugar para os mais "competentes", ou que desenvolvem, ao longo de sua vida, aquelas qualidades técnicas e psicossociais que interessam ao mercado. Cada indivíduo tem que isoladamente negociar o seu lugar e moldar-se às necessidades do mercado e pelo tempo que o mesmo necessita.

Em educação e crise do capitalismo real, destaca-se a natureza e a especificidade da crise do capital e as políticas socialmente regressivas, que degradam a vida da classe trabalhadora. Sob esta base, expõem-se as novas noções que têm no ideário do capital humano sua raiz e a incorporam, mas também aprofundam seu caráter invertido de compreender a realidade. Capital humano situa-se ainda no contexto da crença do pleno emprego e da integração (ainda que desigual) de toda força de trabalho. Crença, porque o capitalismo pressupõe um exército de reserva.

Neste contexto, já não se fala em sociedade, mas de mercado ou economias emergentes. Também cunha-se a ideologia da revolução científica e tecnológica que tem como síntese a tese da sociedade do conhecimento. Dentro de uma realidade em que não só a ciência, mas também a informação, está cada vez mais monopolizada privadamente, passando-se a ideia de que todos podem acessar o conhecimento e, portanto, também não há mais classes sociais. No plano da produção flexível já não basta a qualidade, mas exige-se a qualidade total. Esta uma noção que advém da nova realidade da relação capital-trabalho e exige que o trabalhador produza uma mercadoria ou serviço, em menor tempo, 


\section{Trabalhonecessário}

Issn: 1808 - 799X

ano 13 , número $20-2015$

dentro das prescrições e ao menor custo possível. Portanto, que esta mercadoria ou serviço cheguem ao mercado com vantagens competitivas para sua realização.

Deriva dessas noções mais gerais um conjunto de outras que foram aparecendo no vocabulário social e educacional e que incidem política e ideologicamente na hipertrofia do individualismo. O texto Novos fetiches mercantis da pseudoteoria do capital humano no contexto do capitalismo tardio (FRIGOTTO, 2011) completa até o presente o percurso que começa com $A$ produtividade da escola improdutiva. Um esforço na perspectiva de desvelar o que está subjacente a estas noções que expõem o sentido da realidade de forma inversa.

No contexto da produção flexível, amplia-se a substituição de trabalhadores por capital morto e extinção e a flexibilização de direitos, não cabe garantir o direito ao emprego. Trata-se de educar para a empregabilidade e esta depende de cada um. Também desaparece do vocabulário social e pedagógico o termo qualificação. Esta estava ligada a emprego e ao um conjunto de direitos dos trabalhadores os quais contavam com sindicatos fortes que defendiam seus interesses. O empregável forma-se por competências e estas são aquelas requeridas pelo mercado. O trabalhador, individualmente, que busque estar atento ao que o mercado espera dele. Por consequência quem deve, de forma gradativa, orientar, inclusive as escolas estatais púbicas, os currículos, os conteúdos e os métodos de ensino e de avaliação são institutos vinculados aos setores produtivos privados. Mas se o desejo for ser patrão de si mesmo, o recado cínico é: busque ser empreendedor.

Este conjunto de noções e outras em construção tem como resultado criar a crença de que nascer numa palafita ou nas periferias dos grandes e médios centros urbanos nada tem a ver com classe social, relações de poder e de dominação. Afinal para a ideologia neoliberal, o sucesso depende do esforço e do investimento individual ${ }^{11}$. Idiota é aquele pai, não importa se desempregado ou

${ }^{11}$ As teses do pós-modernismo, fortemente presentes nas ciências sociais e humanas a partir da década de 1980, reforçam as visões ultra-individualistas da doutrina liberal e neoliberal. Fredric 


\section{Trabalhonecessário}

Issn: 1808 - 799X

ano 13, número $20-2015$

com um salário mínimo, que não coloca seu filho na melhor escola e na melhor universidade, de preferência no exterior. O monopólio da mídia, parte das grandes corporações do capital, encarrega-se de, permanentemente, afirmar essas ideias de sorte que, ao final, levam os pais e os filhos da classe trabalhadora a serem tidos como os únicos culpados por sua situação.

Este percurso de produção, de caráter mais geral, tem como foco o embate na concepção de ser humano, sociedade, conhecimento, trabalho e educação, como tendência na relação da sociabilidade ou sociometabolismo do capital com as concepções e políticas de educação, sobretudo escolar. Com base nesta produção e no diálogo fecundo com uma ampla produção crítica no campo das ciências sociais e da educação e vínculos com os movimentos sociais, sindicatos e suas lutas, incluída a disputa das concepções das políticas educacionais, minhas análises centram-se cada vez mais na particularidade da sociedade brasileira.

Uma sociedade, como a define Florestan Fernandes, de capitalismo dependente, expressão de uma burguesia que nunca a defendeu e que, até o presente, se associa ao grande capital. Disto resulta uma sociedade em que o aumento da riqueza, para poucos, mantém e amplia a pobreza da maioria. Uma burguesia que produz a miséria e se alimenta dela, como sentencia Francisco de Oliveira (2003).

Assim, concomitante ao esforço de apreensão da anatomia mais geral da relação entre relações sociais econômicas e as concepções e políticas educativas, produzi análises com foco na relação sociedade, trabalho e educação dentro da realidade brasileira. Os eixos centrais dessa produção podem ser apreendidos na obra organizada por Ciavatta (2012), na qual resgata, do conjunto de minha produção até o momento, textos de caráter teórico epistemológico e de embate político prático. Essas análises, em diálogo com o pensamento crítico,

Jameson (1996) mostra que o pensamento pós-moderno é expressão cultural da forma fragmentada que assume o capitalismo atualmente. 


\section{Trabalhonecessário}

Issn: 1808 - 799X

ano 13 , número $20-2015$

refletem a especificidade conflitos e lutas na sociedade e na educação, nas duas últimas décadas do século $\mathrm{XX}$ e na primeira do século $\mathrm{XXI}$.

Dos textos selecionados por Ciavatta, sublinho dois por sinalizarem a necessidade de aprofundarmos, de forma fraterna e generosa, as diferentes apropriações do legado de Marx e de seus maiores intérpretes, Engels, Lênin e Gramsci, e as diferentes posições no plano da disputa no terreno adverso e contraditório e na particularidade da luta de classes no Brasil. Trata-se, na verdade, de como mover-se dentro da ordem capitalista, numa das sociedades mais desiguais do mundo, tendo como horizonte a sua superação para uma sociedade socialista. O primeiro, A polissemia da categoria trabalho e a batalha das ideias nas sociedades de classe (FRIGOTTO, 2009), tem seguinte questão básica em debate: quem constitui atualmente, afinal, a classe trabalhadora legítima, herdeira do projeto revolucionário? O segundo, Os circuitos da história e o balanço da educação no Brasil na primeira década do século XXI (FRIGOTTO, 2011), efetiva um balanço dos oito anos do governo Luiz Inácio Lula da Silva.

Um governo que, como assinala Francisco de Oliveira tinha uma base social que lhe permitiria "uma espécie de quarta refundação da história nacional, isto é, um marco de não retorno a partir do qual impõem-se novos desdobramentos" (OLIVEIRA, 2003, p. 3). Os desdobramentos a que se refere implicariam confrontar os interesses da classe burguesa brasileira e seu histórico projeto de sociedade. Já a partir de 2004, e ao longo dos oito anos desse governo, Oliveira reitera análises críticas cuja síntese é de que o que resultou é uma hegemonia às avessas (OLIVEIRA; BRAGA; RIZEK, 2010). Vale dizer, em vez de potencializar e politizar as forças que o elegeram para construir o marco de não retorno, costurou alianças e políticas de conciliação de classes. Além da despolitização das massas, gerou-se um duplo enfraquecimento da esquerda. Por um lado, um processo de transformismo de quadros que eram da esquerda e, por outro, a fragmentação - com novos partidos e centrais sindicais.

Quer pelo avanço avassalador das forças do capital, que impõe uma profunda regressão nos direitos sociais, quer pela hegemonia às avessas ficou 


\section{Trabalhonecessário}

Issn: 1808 - 799X

ano 13 , número $20-2015$

extremamente difícil a disputa política na defesa das mudanças que, dentro da ordem capitalista, buscam sua superação. Nos dois textos acima, que retomo da coletânea organizada por Ciavatta, destaco a dificuldade, no plano teórico e na ação política concreta, do pensamento de esquerda, especialmente da educação, de lidar com a contradição. O caminho da hegemonia às avessas, que se aprofunda no governo de Dilma Rousseff, potencia esta dificuldade e pode estar reforçando uma tendência do refúgio em debates apenas teóricos e de viés academicista. Ou seja, longas e eloquentes discussões abstratas sem levar em consideração as condições objetivas e a necessidade da disputa no campo das ações concretas. Este um terreno sempre repleto de contradições, pois ligado na dialética do real e no plano da luta de classes e não na dialética formal do discurso.

\section{Tensões entre a teoria e a prática e controvérsias do percurso}

Do balanço a que fui interpelado fazer do livro $A$ produtividade da escola improdutiva, cuja questão central porposta foi a de explictar as lições que ficaram 30 anos depois, em forma de síntese, sublinharei: o que pecebo que permanece; o que se altera e a sua a direção; e, ainda, procurei destacar o ponto mais crucial das lições deste percuros que é a dificuldade do campo de esquerda de transitar da reflexão teórica, que tem que ir à raiz, e a construção de uma unidade no plano político, mesmo que no discenso, para construção de uma agenda de intevenção concreta nas lutas mais amplas da sociedade brasilieria e as específicas da educação e que interessam à classe trabalhadora.

Este último ponto foi central na vida e obra de Marx, Lênin e Gramsci, nossas grandes referências clássicas e que não faltou, no seu tempo, de serem tachados de reformistas por buscarem unidade no campo da ação política. Esta preocupação, presente no texto-base de minha exposição no INTERCRÍTICA II, ganhou ênfase a partir da exposição oral do colega Paolo Nosella na mesa aqui 


\section{Trabalhonecessário}

Issn: 1808 - 799X

ano 13, número $20-2015$

referida. Ao final de sua exposição oral trouxe um contraponto entre a concepção da escola unitária e o ensino médio integrado e construiu a tipologia: visão conservadora, dos defensores da dualidade da educação; visão reformista, dos defensores do ensino médio integrado e visão revolucionária, os que defendem a perspectiva da escola unitária. Pontuarei, ao final, no que entendo pertinente em suas análises e o que vejo como equivocado nesta crítica.

Das lições que ficaram, um primerio aspecto a sublinhar é de que a base teórica centrada no materiaismo histórico, que permitiu buscar o que está subajacente à formulação da "teoria" do capital humano na concepção de ser humano, sociedade, ciência, trabalho e educação, não só permaneceu válida como ganhou mais densidade ao longo dos últimos trinta anos.

O que foi se adensando ao longo dessas três décadas é que os processos de conhecimento nas sociedades cindidas em classes sociais não são neutros e fazem parte da luta de classe. As visões idealistas, racionalistas, empiricistas e funcionalistas interessam à classe detentora do capital, pois as concepções de realidade social e os métodos de abordá-la naturalizam a sociedade capitalista e não revelam a sua natureza fundada na exploração e na alienação. Em contrapartida, o método dialético materialista histórico busca o que está subjacente ou as determinações que produzem a realidade humana, em todas as suas dimensões e na perspectiva da superação do capitalismo.

Deste aspecto decorre que as análises, que tendem ir à raiz de como se produz a realidade, não resultam da soma de vários referenciais e métodos nem de uma negociação. Isto, contudo, nada tem a ver com dogmatismo. Pelo contrário, Marx, neste sentido, é um exemplo de como ele se apropriou criticamente de análises dos seus contrários: na "economia política inglesa", na "filosofia alemã" e no "socialismo utópico francês".

Também permanece central a relação entre produção do conhecimento, processos educativos e consciência de classe ou da relação teoria e prática. Retiro duas sinalizações de José Barata-Moura sobre a produção da ciência da história e da relação teoria e prática em Marx, pois talvez esteja aí o ponto nodal 


\section{Trabalhonecessário}

Issn: 1808 - 799X

ano 13, número $20-2015$

da dificuldade do pensamento crítico em nosso campo educacional para transitar do campo da produção teórica à ação político prática, deixando para os intelectuais do capital tomar por assalto o fundo público e orientar, no conteúdo, no método e na forma a educação que convém ao mercado.

Ao tratar da cientificidade do saber Barata- Moura observa que, para Marx, a ciência não é obra individual, mas de um esforço coletivo de um povo. Do memso modo a cientificidade não acaba na análise da relaidade, mas ná práxi ${ }^{12}$.

A partir do legado teórico de Marx, de Lênin e de Gramsci e da ação concreta, fica claro a importância do trabalho coletivo pautado, ao mesmo tempo, pelo rigor crítico e pela solidariedade de classe, sabendo-se que a consciência política do pertencimento da classe trabalhadora (consciência de classe) constróise na práxis. Trata-se de um aprendizado na luta política concreta contra os processos de exploração e expropriação da classe trabalhadora, por meio de organização para fazer valer direitos negados.

$\mathrm{Na}$ realidade brasileira dos últimos trinta anos, o Movimento dos Trabalhadores Sem Terra (MST) é quem traduz com mais clareza e resultados esta relação. A comprovação disto é a sistemática criminalização de suas legítimas lutas e a aplicação implacável do direito positivo ou do direito da propriedade privada dos meios e instrumentos da produção e reprodução da vida matéria.

O segundo aspecto diz respeito ao que se alterou nestas três décadas no plano internacional e brasileiro na base material e política das relações sociais capitalistas. No plano produtivo tem-se a apropriação privada pelo capital da ciência e do salto tecnológico, que junta microeletrônica e informação, alteram radicalmente a forma de operar com a matéria e, portanto, com os processos de produção e de organização da produção. No plano político, vivemos o colapso do socialismo real e a disseminação da ideologia neoliberal ou neoconservadora.

12 O leitor que queira aprofundar esta questão central entre teoria e prática em Marx ver: Marx e a cientificidade do saber (BARATA-MOURA, 1998, p. 67-145). 


\section{Trabalhonecessário}

Issn: 1808 - 799X

ano 13, número $20-2015$

Disto resulta uma regressão social em todas as esferas da vida, recaindo, sobretudo, na classe trabalhadora.

Esta mudança permite ao capital efetivar um rolo compressor sobre os trabalhadores, como observa Danièle Linhart (2007) em seu livro A desmedida do capital. No campo educativo, mais grave do que a expansão do mercado privado, é a direção no conteúdo, método e forma da educação pública dentro de uma concepção mercantil. Aqui, um duplo e mais duro desafio. No campo teórico desafia-nos o esforço de apreender, para além da aparência, o sentido do movimento da realidade. No plano político é urgente a construção de uma agenda que possa não apenas barrar a mercantilização, mas retomar o espaço da esfera pública. Único espaço, mesmo que restrito, de garantia de direitos universais.

Dos dois pontos destacados acima, retiro uma observação mais geral da produção acadêmica do campo crítico em nossa área e de modo generalizado nas ciências sociais. Com efeito, neste particular, cabe uma autocrítica à boa parte da produção acadêmica que se faz nas universidades e que se alimenta de longos debates abstratos, mas sem nenhum vínculo imediato ou mediato com as lutas e com as ações que buscam, de dentro de velhas e opacas estruturas sociais e educacionais, construir mudanças que alteram estas estruturas na perspectiva de sua superação. Trata-se de análises, mesmo quando bem intencionadas, que acabam escorregando para julgamentos morais, ou posturas dogmáticas e, não raro, por julgamentos apressados do que seja revolucionário ou reformista. O que fica ausente nestas análises é o caráter contraditório de toda a realidade histórica. Nenhuma mudança histórica começa pelo novo, mas pela dialética de superação das velhas estruturas e relações sociais.

Com rara precisão Karel Kosik (1969) nos aponta duas tendências igualmente nefastas e que merecem atenção dos pesquisadores que atuam nas universidades e que buscam vínculos com os movimentos e as lutas da classe trabalhadora, e que traduzo aqui como: esquerdismo e pragmatismo oportunista. Por um lado, o esquerdismo, Kosik o caracteriza pela figura da bela alma. Tratase de posturas teóricas abstratas que desvinculadas das lutas concretas da 


\section{Trabalhonecessário}

Issn: 1808 - 799X

ano 13, número $20-2015$

classe trabalhadora assumem uma visão moralista para a qual tudo é reformismo e que conduz a uma posição imobilista. Por outro lado, a figura do comissário, que designa a postura dos que assumem uma atitude política pragmática, oportunista, em defesa de seus próprios interesses.

É dentro deste contexto que a tipologia feita por Nosella para criticar os pesquisadores que subsidiaram a proposta do Ensino Médio Integrado no contexto do embate de forças em disputa no início do governo de Luiz Inácio Lula da Silva, pode ser entendida, à luz do materialismo histórico, teórica e politicamente não procedente ${ }^{13}$.

No âmbito teórico, a tipologia tem sua gênese em referenciais funcionais estruturalistas e no terreno discursivo das antinomias. Não lida, pois, com a historicidade e as contradições e mediações que lhes são inerentes. Ou seja, trata-se de uma forma argumentativa que tem efeito discursivo potente, mas impotente para captar o caráter dialético e, portanto, sempre contraditório e lacunoso da realidade histórica e da relação de forças concretas na práxis política.

Em artigo publicado quatro meses após o INTERCRÍTICA II, Paolo Nosella (2015) reitera as críticas ao ensino médio integrado em dois aspectos básicos. Primeiro, por interpretá-lo como sendo uma proposta de profissionalização precoce e, segundo, criticando o termo travessia por este equacionar " o ponto de saída e o ponto de chegada ou, em termos atuais, equacionando a travessia da superação da sociedade neoliberal para a sociedade socialista" (NOSELLA, 2015, p 139).

Pelo que destaco na nota 13, tenho muito mais concordâncias que discordâncias na produção acadêmica de Paolo Nosella. No texto e no debate

\footnotetext{
${ }^{13}$ De imediato destaco a relevância e contribuição singular da produção teórica de Paolo Nosella no pensamento educacional nas três décadas contempladas no debate do INTERCRÍTICA II. Devo ao Paolo, entre muitas de suas contribuições, a leitura de seus textos, as suas observações críticas num debate em que me cobrou um olhar mais agudo sobre a particularidade da realidade brasileira em minhas análises. Refiro-me, aqui, ao debate no interior do GT Trabalho e Educação da Associação Nacional de Pesquisa e Pós-Graduação em Educação (ANPED) e do qual resultou a coletânea Trabalho e Educação: perspectivas de final de século (FRIIGOTTO. Org., 1998), atualmente na $12^{\mathrm{a}}$ edição.
} 


\section{Trabalhonecessário}

Issn: $1808-799 X$

ano 13, número $20-2015$

em questão, nenhuma discordância à tese que o ensino médio "é uma fase estratégica do sistema escolar" e que o mesmo "possui sentido pedagógico próprio" (op.cit. p.121). Do mesmo modo, concordância em relação à não profissionalização precoce.

A discordância está na sua interpretação de ensino médio integrado como profissionalizante e do sentido dado ao termo travessia. Na coletânea Ensino Médio Integrado: concepção e contradições (FRIGOTTO; CIAVATTA; RAMOS, 2005) há um embate imediato com a dualidade e com a contraposição entre a formação geral e específica, técnica e política e, ao mesmo tempo, com a profissionalização precoce. Daí seus fundamentos serem a ciência, o trabalho e a cultura. O subtítulo realça que o ensino médio integrado resulta de um terreno contraditório e de disputa política num contexto de democracia restrita ${ }^{14}$.

Assim entendido, o que se afirma é que o mesmo pode (grifos meus) constituir-se em travessia à educação politécnica e à escola unitária. Aqui o termo travessia, ao contrário do que postula Nosella, não equaciona o ponto de partida e de chegada. A metáfora travessia, no contexto da análise, sinaliza o mover-se na luta política no âmbito contraditório do velho e do novo e na perspectiva de superação da sociedade de classes.

Curiosamente, Istvam Mészàros (2014), analisando o caráter cada vez mais destrutivo da atual ordem socioeconômica e política do sistema capital, utiliza uma metáfora no mesmo sentido de travessia como título ao seu último livro traduzido no Brasil - A montanha que devemos escalar. O que aprendemos em Marx é que o ponto de chegada inequívoco, a travessia ou montanha a galgar, é a necessária superação da sociedade capitalista e a construção de uma nova sociedade, sem classes e sem exploração, cujo início se dá dentro da velha ordem.

\footnotetext{
14 No mesmo ano, estes mesmos autores publicaram, na Revista Eletrônica Trabalho Necessário (n.3, Ano 3, 2005), um texto cujo título e conteúdo indicam o terreno da disputa teórica e política: Gênese do Decreto 5.154/2004: um debate no contexto controverso da democracia restrita.
} 


\section{Trabalhonecessário}

Issn: 1808 - 799X

ano 13 , número $20-2015$

O termo reformista, no contexto do debate no Brasil, em verdade quer dizer que se trata de uma proposta que alimenta o statu quo das relações sociais e da educação no Brasil e não de mudanças dentro da ordem na perspectiva de sua superação. O paradoxal é que na leitura da proposta do ensino médio integrado feita por Cláudio de Moura Castro, grande defensor da dualidade e da profissionalização precoce e mentor do Decreto 2.208/1996, ele a vincula à concepção de escola unitária e de educação politécnica de Gramsci. Reitero o final da nota 4 deste texto.

Após a mudança de governo, entraram no MEC os inconformados com a separação. Tentaram voltar atrás, mas, em virtude da grita, somente as escolas federais tornaram a integrar o acadêmico ao técnico. As razões para juntá-los permanecem misteriosas para a cabeça simplória deste autor. A bandeira desfraldada era uma tal "politecnia", criada por Gramsci, lá pelos anos 1920, enquanto morava na cadeia. Prescrevia um ensino combinando as disciplinas técnicas com as acadêmicas e com o trabalho. Mais que isso, não entendi.

No debate sobre este tema e outros, no âmbito do pensamento de esquerda, valeria observar que Marx foi acusado de ser conservador por um grupo de jovens hegelianos de Berlim (Os livres) por ele não incluir seus textos quando era editor-chefe de reportagem do jornal Rheinische Zeitung, em Colônia. Tratava-se de um jornal liberal de oposição ao poder político da nobreza e que representava interesses de várias ordens, de industriais que o financiavam, mas também de correntes de esquerda. A razão da não inclusão era que os artigos necessitavam "mais atenção ao real estado de coisas, mais conhecimento específico" (MARX, apud GABRIEL, 2013, p.67).

Dramático, por sua vez, é de que as forças do capital e seus intelectuais não pararam na gritaria a que se refere Castro, e, principalmente na última década, estruturaram-se organicamente sob o cínico slogan: Todos pela Educação. Por três razões relacionadas, avançaram em todos os espaços dos aparelhos do Estado stricto sensu e nos aparelhos de hegemonia na sociedade 


\section{Trabalhonecessário}

Issn: 1808 - 799X

ano 13, número $20-2015$

civil, mormente pelas grandes corporações da mídia. Por um lado, por estar a classe burguesa brasileira unida no que é fundamental: o interesse de classe, mesmo que haja conflitos entre as suas diferentes frações. Por outro, um governo que renunciou representar um projeto de sociedade e de educação da grande base social que o elegeu e que despolitizou e fragmentou esta base não só deixando o campo aberto ao Todos pela Educação, mas sendo parte ativa na adoção de suas concepções. Por fim, no caso do MEC e de diferentes órgãos a ele vinculados, os que assumiram algum posto intermediário e que buscavam sustentar concepções e políticas dos movimentos sociais, não tinham apoio do governo e nem dos que produzem as análises críticas nos programas de pósgraduação em educação e outros espaços. A maioria saiu espontaneamente ou foi exonerada.

Em síntese, o que em 1977 era um slogan do Senai, como assinalei na dissertação de mestrado acima referida, ensinar o que serve aos industriais hoje amplia-se e consolida-se em uma educação que serve ao mercado e ao capital. $O$ ensino médio integrado já não ameaça, tão pouco há forças em movimento concreto na perspectiva da escola unitária e da educação politécnica, salvo na agenda e na luta concreta de parte das escolas dos assentamentos do MST e de alguns sistemas de ensino. A passividade diante da meritocracia e do produtivismo, que dela decorre e a alimenta, é um sintoma de quebra da solidariedade coletiva no campo da esquerda, elo fundamental em qualquer luta contra-hegemônica. O que tramita no Congresso Nacional, com apoio do MEC e sob a direção do Todos pela Educação, é uma proposta de reforma do ensino médio que retroage às leis da equivalência da primeira metade do Século $X X$.

O INTERCRÍTICA II, pelo número de grupos de pesquisa inscritos de todas as regiões e a sua produção vinculada com os desafios locais, regionais e nacionais, sinaliza algo que necessitamos potenciar: o rigor na produção teórica e seu vínculo concreto com a práxis dos movimentos e forças sociais, que têm como horizonte a superação da sociedade de classes e a construção do socialismo. Uma travessia que a história da luta de classes nos mostra ser 


\section{Trabalhonecessário}

Issn: 1808 - 799X

ano 13 , número $20-2015$

íngreme e pautada no embate da dialética do novo que se gesta nas contradições do velho. Se o balanço dos textos que ensejou a mesa Três décadas de produção na área de trabalho e educação no Brasil: que lições ficaram?, e o conjunto de debates do INTERCRÍTICA II nos interpelar sobre a natureza de nossa produção teórica e seu vínculo com as lutas que interessam à classe trabalhadora, mesmo que pequenas, parciais e, certamente contraditórias, , o empenho valeu apena.

\section{Referências bibliográficas}

ALTVATER, Elmar. O fim do capitalismo tal qual o conhecemos. Rio de Janeiro: Civilização Brasileira, 2010.

BARATA-MOURA, José. Materialismo e subjetividade. Estudos em torno de Marx. Lisboa: Editorial Avante, 1998.

BLACKBURN, Rubin. Depois da queda: o fracasso do comunismo e o futuro do socialismo. Rio de Janeiro: Paz e Terra, 1992, p.93-106.

CASTRO, Cláudio de Moura. O dilema do ensino técnico. São Paulo: Revista Veja. 15 de outubro de 2012.

CIAVATTA, Maria. Gaudêncio Frigotto - um intelectual crítico nos pequenos e nos grandes embates. Belo Horizonte: Autêntica, 2012.

DREYFUS, René. 1964: a conquista do estado. Petrópolis, RJ: Vozes, 1981.

FERNANDES, Florestan. A revolução burguesa no Brasil: ensaio de interpretação sociológica. Rio de Janeiro: Zahar, 1974.

FRIGOTTO, Gaudêncio. Efeitos cognitivos da escolaridade do Senai e da escola acadêmica: existe uma escola para cada classe social? 1977. Dissertação. Instituto de Estudos Avançados em Educação (lease), Fundação Getulio Vargas, Rio de Janeiro, 1977.

. Educação e crise do capitalismo real. São Paulo: Cortez, 1ํㅡ ed, 1995.

- A polissemia da categoria trabalho e a batalha das ideias nas sociedades de classe. Revista Brasileira de Educação. Rio de Janeiro: Anped. v.14, n.40, p, 168-194, jan./abr. 2009.

- Os circuitos da história e o balanço da educação no Brasil na primeira década do século XXI. Revista Brasileira de Educação. Rio de Janeiro: Anped. v.16, n.46, p. 235-274, jan./abr. 2001

. Fazendo pelas mãos a cabeça do trabalhador: o trabalho como elemento pedagógico na formação profissional. Cadernos de Pesquisa, Fundação Carlos Chagas, São Paulo: Cortez (47): p-38-45, nov./1983. 


\section{Trabalhonecessário}

Issn: 1808 - 799X

ano 13, número $20-2015$

A produtividade da escola improdutiva: um (re)exame das relações entre educação e estrutura econômico-social capitalista. São Paulo: Editora Cortez, 1984. $1^{\text {a }}$ ed.

. Novos fetiches mercantis da pseudoteoria do capital humano no contexto do capitalismo tardio. In; ANDRADE, Juarez de e PAIVA, Lauriana G. de (orgs.). As políticas públicas para a educação no Brasil contemporâneo. Juiz de Fora: Editora UFJF, 2011, p.18-35.

FRIGOTTO, Gaudêncio; CIAVATTA Maria; RAMOS, Marise. Ensino médio tegrado: concepção e contradições. São Paulo: Cortez, 2005.

JAMESON, Fredric. Pós-modernismo. A lógica cultural do capitalismo tardio. São Paulo: Editora Ática, 1996.

HARVEY, David. O enigma do capital e as crises do capitalismo. São Paulo: Editora Boitempo, 2010.

. O novo imperialismo. São Paulo: Editora Loyola, 2013.

LINHART, Danièle. A desmedida do capital. São Paulo: Boitempo, 2007.

MÉSZAROS, Istvam. A montanha que devemos escalar. São Paulo: Boitempo, 2014.

NOSELLA, Paolo. Ensino médio unitário ou multiforme? Revista Brasileira de Educação, v.20, n.60, jan.-mar. 2015.

OLIVEIRA, Francisco de. Crítica à razão dualista. O ornitorrinco. São Paulo: Boitempo, 2003.

A hegemonia às avessas. In; OLIVEIRA, Francisco de; BRAGA, Ruy;

RIZEK, Sibele. Hegemonia às avessas. São Paulo: Boitempo, 2010, p.21-29.

PARIS. Carlos. O animal cultural. São Carlos: Editora da UFSCar, 2002.

WILLIAMS, Raymond. Cultura e materialismo. São Paulo: Unesp, 2011.

Recebido em 10 de outubro de 2014 Aprovado em 13 de novembro de 2014 